\title{
Immunological characterization of the American cockroach allergen Per a 9 expressed in baculovirus-infected insect cells
}

\author{
HAI-WEI YANG ${ }^{1,2 *}$,WEI ZHANG ${ }^{3 *}$,WEI-WEI NI I ${ }^{*}$, MIN JIN $^{l}$, SHAO-HENG HE ${ }^{4}, J I-F U ~ W E I^{l}$ \\ ${ }^{1}$ Research Division of Clinical Pharmacology, the First Affiliated Hospital of Nanjing Medical University, Nanjing, China \\ ${ }^{2}$ Department of Urology, the First Affiliated Hospital of Nanjing Medical University, Nanjing, China \\ ${ }^{3}$ Department of Clinical Laboratory, the First Affiliated Hospital of Nanjing Medical University, Nanjing, China \\ ${ }^{4}$ Allergy and Clinical Immunology Research Centre, the First Affiliated Hospital of Jinzhou Medical University, Jinzhou, China
}

"These authors contributed equally to this work.

\begin{abstract}
American cockroach (CR) allergy has been recognized as important IgE-mediated type I hypersensitivity. Per a 9 is an arginine kinase, reacting with IgE in sera of all CR allergic Thai patients. Per a 9 gene was cloned and expressed in eukaryotic systems (baculovirus-infected insect cells). The expressed Per a 9 was purified by Nickel column. The antigenicities were analyzed by ELISA, immunoblot analysis and basophile activation test. The results show that 13 out of $16(81.3 \%)$ sera from American $C R$ patients reacted to Per a 9, confirming that Per a 9 is a major allergen of $C R$. The IgE reactivity of Per a 9 in the sera from American CR patients was increased 8.3-fold in comparison with the sera from healthy controls. Per a 9 at $1.0 \mu \mathrm{g} / \mathrm{ml}$ induced an approximately up to 5.6-fold increase in CD63 and CCR3 double positive cells when incubating with passively sensitized basophils from by sera from American CR patients.
\end{abstract}

Key words: American cockroach, allergen, Per a 9, insect cell, IgE reactivity.

(Centr Eur J Immunol 2019; 44 (3): 322-326)

\section{Introduction}

Allergens derived from American cockroach (Periplaneta Americana - Per a) have been recognized as major triggering factors for allergic respiratory symptoms [1]. Epidemiological studies revealed that the prevalence of cockroach (CR) allergy ranges from $17 \%$ to $41 \%$ in the USA [2, 3]. In China, in total $25.7 \%$ of allergy patients are skin prick test (SPT) positive to the American CR [4]. Moreover, CR allergens are found in $11 \%$ to $98 \%$ of dust samples collected from 9 cities across the southern and tropical regions of China [5].

CR allergens consist of a wide group of proteins with diverse structures and biological functions. At least twenty-two immunoglobulin E ( $\operatorname{IgE}$ ) binding allergens were identified in American CR [6], but only a few of these allergens including Per a 1 (enzyme related with digestion) [7], Per a 2 (aspartic protease) [8], Per a 3 (arylphorin) [9], Per a 4 (lipocalin) [10], Per a 5 [11], Per a 6 (troponin-C)
[12], Per a 7 (tropomyosin) [13], Per a 9 (arginine kinase) $[14,15]$, Per a 10 (serine protease) $[16,17]$, Per a 11 ( $\alpha$-amylase) [18] and Per a 12 (chitinase) [18] are characterized. Among these, Per a 9 is an arginine kinase, purified from the American CR extract by the monoclonal antibody based-affinity chromatography reacting with IgE in sera of all CR allergic Thai patients [14]. Moreover, Per a 9 was successfully expressed in E. coli and purified by 6-His-tag purification system $[15,19]$. The recombinant allergen was identified as its affinity to IgE antibodies from the CR-allergic patient sera by western blotting and ELISA [15, 19].

Many, but not all allergens expressed from cDNA have shown a considerable IgE binding reactivity that seems to be comparable to their natural counterparts. The majority of these recombinant allergens are produced in E. coli, but unfortunately, the amount and/or reactivity is sometimes reduced when the allergen is purified and subjected to immunological and biochemical assays [20]. To overcome some of these problems, eukaryotic expression systems such as yeast and

Correspondence: Prof. Ji-Fu Wei, Research Division of Clinical Pharmacology, the First Affiliated Hospital, Nanjing Medical University, 300 Guangzhou Rd, 210029 Nanjing, China, e-mail: weijifu@ hotmail.com; Prof. Shao-Heng He, Allergy and Clinical Immunology Research Centre, the First Affiliated Hospital of Jinzhou Medical University, No. 2, Section 5, Renmin St., Guta District, Jinzhou, Liaoning 121001,

China, e-mail: shoahenghe@hotmail.com

Submitted: 5.12.2016; Accepted: 28.12.2016 
baculovirus in insect cells have been used [21]. Nowadays, several insect cell lines and a variety of baculovirus-based expression systems are available for the production of pharmaceutically relevant proteins. Currently, there is no report about CR allergen Per a 9 expressed in insect cells using a baculovirus expression system. The aim of the present study is to generate recombinant Per a 9 (rPer a 9) using a eukaryotic expression system (baculovirus-infected insect cells) and characterize its biochemical and immunologic properties.

\section{Material and methods}

\section{Patients and samples}

A total of 16 allergic rhinitis patients with positive STP (allergens were supplied by ALK-Abelló, Inc., Denmark) and positive serum IgE test to American CR extract (by using ImmunoCAP assay [Pharmacia Diagnostics AB, Uppsala, Sweden]), and 6 healthy controls (HCs) were recruited in the study. The informed consent from each volunteer according to the Declaration of Helsinki and agreement with the ethical committee of the First Affiliated Hospital of Nanjing Medical University was obtained. Serum (4 ml) from peripheral venous blood was collected from each patient and $\mathrm{HC}$ for Western blot analysis.

\section{Expression and purification of Per a 9 in baculovirus-infected insect cells}

The cDNAs encoding Per a 9 was prepared as previously reported [15]. The identified Per a 9 gene was then subcloned into pFastBac1 vector (Novagen, Madison, Wisc., USA) using EcoR I and Sal I sites and the resulted construct was transformed into $E$. coli strain DH10Bac to generate recombinant bacmid. The positive colonies were selected and followed by PCR identification. The recombinant Bacmid was transfected into sf-9 cells by using Cellfectin (Invitrogen Corporation, Carlsbad, USA), and incubated in HyQ liquid medium (HyClone, Logan, USA) for 5-7 days at $27^{\circ} \mathrm{C}$ until the cells got swollen. The supernatant was collected and designated as P1 viruses. Sf-9 cells were then infected with P1 viruses at the MOI of 1 , and collected when they got swollen. The cell pellet was lysed, and centrifuged at $12,000 \times \mathrm{g}$ at $4^{\circ} \mathrm{C}$ for $20 \mathrm{~min}$ before the supernatant being collected. The supernatant was loaded on the Nickel column (Genscript, Nanjing, China), washed with running buffer containing $50 \mathrm{mM}$ Tris- $\mathrm{HCl}$, $300 \mathrm{mM} \mathrm{NaCl}$ and $5 \%$ glycerol ( $\mathrm{pH} 8.0)$, and eluted with elution buffer containing $50 \mathrm{mM}$ Tris- $\mathrm{HCl}, 300 \mathrm{mM} \mathrm{NaCl}$, $250 \mathrm{mM}$ imidazole and 5\% glycerol ( $\mathrm{pH} 8.0)$. The eluted fractions were obtained and identified as Per a 9.

\section{Immunoreactivity of human sera with Per a 9}

A 96-well plate was coated with $100 \mu \mathrm{l} /$ well of Per a 9 $(10 \mu \mathrm{g} / \mathrm{ml})$ in coating buffer $(50 \mathrm{mM}$ sodium carbonate buffer, $\mathrm{pH}$ 9.6) and incubated at $4^{\circ} \mathrm{C}$ overnight. Human se- rum samples (1 : 20 dilution in PBS-Tween with 2\% BSA) were then added to the plates for $2 \mathrm{~h}$ at room temperature. After IgE binding, plates were incubated with horseradish peroxidase-labeled goat anti-human $\operatorname{IgE}(1: 2500$ dilution) (KPL, Inc., Maryland, USA) and the color was developed with tetramethylbenzidine peroxidase substrate. The plates were read on a microplate reader at absorbance of $405 \mathrm{~nm}$. The cutoff value was calculated as the mean of the negative controls plus 2 SDs.

\section{Immunoblot analysis of IgE reactivity}

Immunoblot assay for the IgE binding activity of Per a 9 to the sera of patients with American CR allergy was performed as previously described [22, 23]. Recombinant Per a $9(5 \mu \mathrm{g})$ was added to a SDS-PAGE (gel concentration of $12 \%$ ) under reducing conditions and then transferred to nitrocellulose membranes. The nitrocellulose membranes were incubated with the sera of the patients with American CR allergy ( $1: 5$ to $1: 20$ in PBS-Tween) for $90 \mathrm{~min}$. Following rinsing with PBS, the membranes were incubated with peroxidase-labeled anti-human IgE monoclonal antibody. The positive protein bands were visualized by incubating the membranes with tetramethylbenzidine peroxidase substrate. Two sera collected from $\mathrm{HCs}$ were used as negative controls in the experiment.

\section{Basophil activation test}

Expression of CD63 and CCR3 on basophil surface has been considered as the indicator of basophil activation $[24,25]$. Briefly, peripheral blood mononucleated cells (PBMC) from 4 healthy volunteers were separated by Ficoll-Paque density gradient, and treated with $10 \mathrm{ml} \mathrm{LS}$ (a solution containing 1.3 M NaCl, $0.005 \mathrm{M} \mathrm{KCl}$ and 0.01 lactic acid, $\mathrm{pH}$ 3.9) for $2 \mathrm{~min}$ at $8^{\circ} \mathrm{C}$. After neutralization with $12 \%$ Tris ( $\mathrm{pH} 10.9$ ), non-specific IgE on basophils was stripped off. Then the cells were passively sensitized with sera of the patients with American CR allergy or HCs $\left(n=4,1\right.$ in 10 dilution, $2 \mathrm{~h}$ at $37^{\circ} \mathrm{C}$ ) as described previously [26]. The sensitized cells were then challenged with various concentrations of Per a 9 for $15 \mathrm{~min}$ at $37^{\circ} \mathrm{C}$. CR3-PE-labelled antibody (eBioscience Inc. San Diego, CA, USA) and anti-human CD63-FITC antibody (Invitrogen Corporation, Camarillo, CA, USA) were added to cells. Flow cytometry analysis of CD63 and CCR3 was performed at $488 \mathrm{~nm}$ on a FACSAria flow cytometer (Becton Dickinson, Franklin Lakes, NJ, USA) and analyzed by FACSDiva software.

\section{Statistics}

Data are expressed as mean $\pm \mathrm{SE}$ for the indicated number of independently performed duplicated experiments. Statistical significance between means was analyzed by oneway ANOVA or the Student's $t$ test utilizing the SPSS 13.0 version. A $p<0.05$ was taken as statistically significant. 


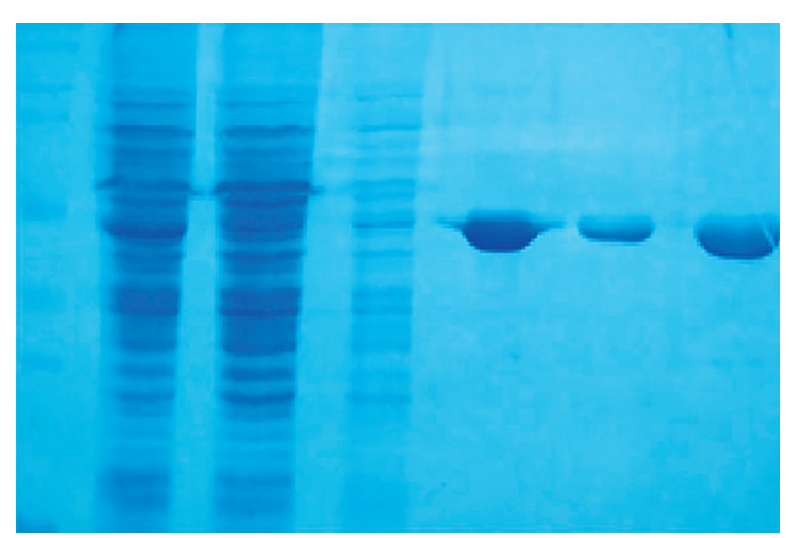

Fig. 1. SDS-PAGE analysis of purification of Per a 9 in baculovirus-infected insect cells through Ni column. Lane M: protein standard. Lane 1: the cytosol. Lane 2: flow through. Lane 3: wash with a buffer containing $50 \mathrm{mM}$ Tris- $\mathrm{HCl}, 300 \mathrm{mM} \mathrm{NaCl}, 5 \%$ glycerol, $\mathrm{pH}$ 8.0. Lane 4: elute with a buffer containing $50 \mathrm{mM}$ Tris- $\mathrm{HCl}$, $300 \mathrm{mM} \mathrm{NaCl}, 5 \%$ glycerol, 20 mM imidazole, $\mathrm{pH}$ 8.0. Lane 5: elute with a buffer containing $50 \mathrm{mM}$ Tris- $\mathrm{HCl}$, $300 \mathrm{mM} \mathrm{NaCl}, 5 \%$ glycerol, $50 \mathrm{mM}$ imidazole, $\mathrm{pH}$ 8.0. Lane 6: elute with a buffer containing $50 \mathrm{mM}$ Tris- $\mathrm{HCl}$, $300 \mathrm{mM} \mathrm{NaCl}, 5 \%$ glycerol, $250 \mathrm{mM}$ imidazole, $\mathrm{pH}$ 8.0. The arrow represents Per a 9 protein

\section{Results}

\section{Expression and purification of Per a 9 in baculovirus-infected insect cells}

The Per a 9 encoding gene was subcloned into pFastBac1 vector and transformed into E. coli strain DH10Bac to generate recombinant bacmid. The recombinant bacmid was then transfected into Sf-9 cells to generate the

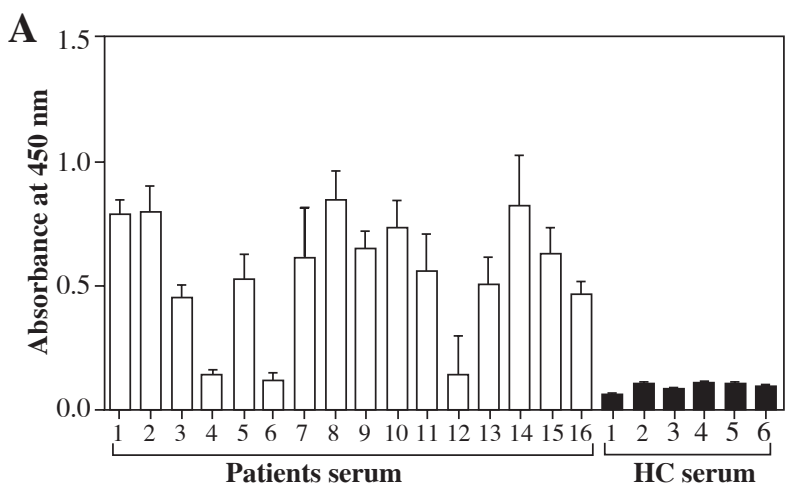

baculovirus. The Per a 9 protein was expressed in Sf-9 cells and purified by Ni column. More than $6 \mathrm{mg}$ recombinant Per a 9 was obtained from 21 cell culture. The purity of the purified Per a 9 was identified by SDS-PAGE. It showed a single band with an apparent molecular weight of $42 \mathrm{kDa}$ (Fig. 1).

\section{Immuno-reactivity to IgE}

In order to determine the allergenicity of Per a 9, we examined the ability of Per a 9 to bind IgE in the sera of the patients with American CR allergy by a direct ELISA technique. The results showed that 13 out of $16(81.3 \%)$ sera from these patients reacted to Per a 9 (Fig. 2A). The IgE reactivity of Per a 9 in the sera from the Per a 9 positive patients was increased 8.3-fold in comparison with the sera from HCs. IgE binding activity of Per a 9 in a representative group of 3 patients and $2 \mathrm{HCs}$ were assessed by Western blot and were illustrated in Figure 2B. IgE binding bands appeared clear with Per a 9 reacting to serum from the patients with American CR allergy. But, Per a 9 did not react to the sera from the HCs.

\section{Per a 9 induced human basophil activation}

Per a 9 at $1.0 \mu \mathrm{g} / \mathrm{ml}$ induced approximately up to 5.6fold increase in CD63 and CCR3 double positive cells when incubating with passively sensitized basophils by sera from the patients with American CR allergy. Per a 9 had no effect on the basophils sensitized by the sera from healthy subjects (Fig. 3).

\section{Discussion}

Numerous insect allergens such as Api m 1 [27], Api m 2 [28] from honeybee venom, Dol m 5 from bald-faced hornet (Dolichovespula maculate) [29], Sol i 3 from ant

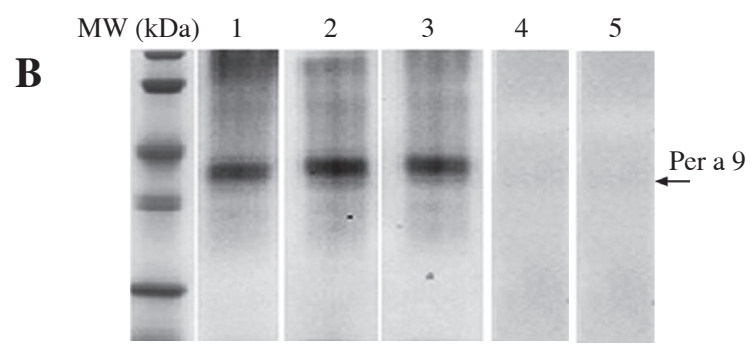

Fig. 2. A) Analysis of specific IgE reactivity of recombinant Per a 9 by direct ELISA. The sera were collected from the patients with American CR allergy and HCs. The values shown are mean \pm SE for the triplicate experiments. B) Western blot analysis of IgE reactivity to Per a 9 sera from the patients with American CR allergy. Lanes 1-3: Per a 9 reacted with the serum from patients 8, 9, 10. Lanes 4-5: Per a 9 reacted with the serum from control 1 and 2 
A

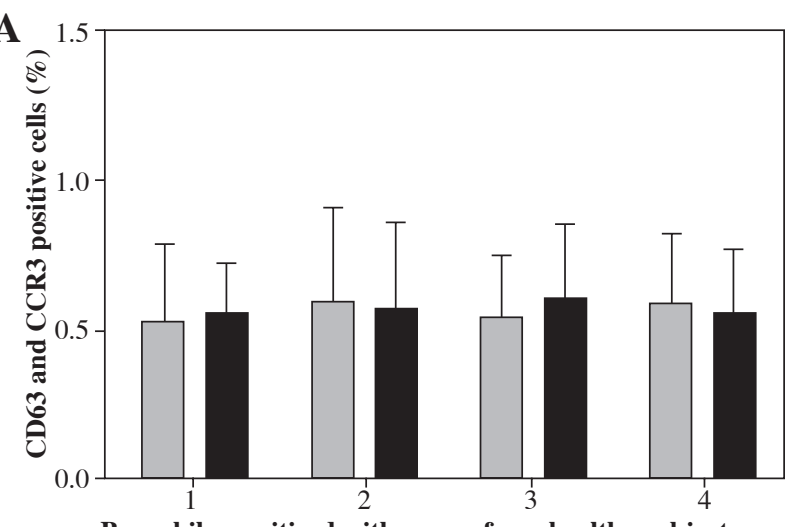

Basophils sensitized with serum from healthy subjects

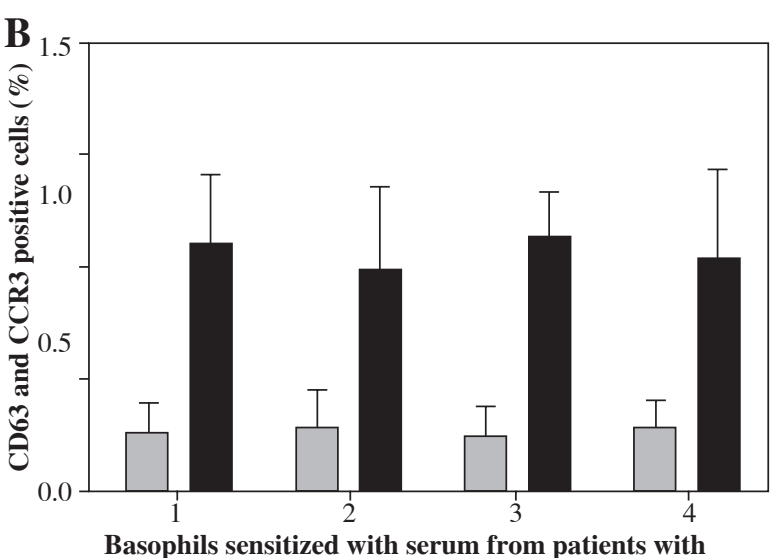

cockroach allergy

$\square$ without Per a 9

with Per a 9

Fig. 3. Induction of basophil activation by Per a 9. After non-specific IgEs on basophils were stripped off, cells from each donor were passively sensitized with sera from 4 different HCs (A) or from 4 different patients with American CR allergy (B), and were then challenged with Per a 9 at $1.0 \mu \mathrm{g} / \mathrm{ml}$. The values shown are mean \pm SE for the sera from 4 different subjects

venom [30], Cul s 1 from the North American midge ( $\mathrm{Cu}$ licoides sonorensis) [31], Der f 1 from house dust mite [32], Blo t 11 from dust-mite (Blomia tropicalis) [33], Lep d 2 from dust mite (Lepidoglyphus destructor) [20], and Aed a 1 [34], Aed a 2 [35] from mosquito (Aedes aegypti) have been successfully expressed in insect cells using a baculovirus expression system. They are reported to possess similar structural and biological activities with their natural forms [36]. Since the CR is an insect, it is feasible to obtain biologically active allergens expressed in baculovirus-infected insect cells. We firstly successfully expressed the American CR allergen, Per a 5 in baculovirus-infected insect cells, proving the advantages of baculovirus-infected insect cells system in expression of American CR allergens [11]. In the present study, we succeeded in producing another biologically active and highly pure American CR allergen, Per a 9, expressed in baculovirus-infected insect cells in a relatively large amount. We found that as little as $2 \mathrm{~L}$ of Sf-9 cell culture medium was able to produce $6 \mathrm{mg}$ of Per a 9, which is enough for the functional study of Per a 9.

The antigenicities of Per a 9 were determined by ELISA, immunoblot analysis and basophile activation test. They appear to be of importance for the allergic reactions induced by CR, and have a potential application for component-based diagnosis of CR allergy. We evaluated the binding of Per a 9 to specific-IgE derived from the sera of patients with American CR allergy and the results showed that $81.3 \%$ of sera from American CR allergy patients react to Per a 9, confirming that Per a 9 is a major allergen in American CR. The basophil activation test we employed herein can represent an in vivo technique for determination of allergenicity of a given allergen. We confirmed that
Per a 9 was an active allergen of CR as it is able to activate basophils which are sensitized by American CR allergic sera. In our case, the expression of the CR allergen, Per a 9, in insect cells will be helpful for CR allergy diagnosis and therapy, especially for patients showing a high reaction to this major American CR allergen.

\section{Acknowledgments}

This project was sponsored by the grants from the Special Fund for Forestry-scientific Research in the Public Interest (201304103), the grants from the National Natural Science Foundation of China (81571568, 31340073 and 81273274); the Priority Academic Program Development of Jiangsu Higher Education Institutions (PAPD), the National "Twelfth Five-Year" Plan for Science \& Technology Support Project (2014BAI07B02), the Innovation team project of Education Department of Liaoning Province (LT2013017), the higher Education Climb scholars Program of Liaoning Province, China (No. LJ2013222) and the Liaoning Province Translational Medicine Research Center for Allergy (No. LK2013041).

The authors declare no conflict of interest.

\section{References}

1. Bernton HS, Brown H (1964): Insect allergy preliminary studies of the cockroach. J Allergy 35: 506-513.

2. Gelber LE, Seltzer LH, Bouzoukis JK, et al. (1993): Sensitization and exposure to indoor allergens as risk factors for asthma among patients presenting to hospital. Am Rev Respir Dis 147: $573-578$. 
3. Rosenstreich DL, Eggleston P, Kattan M, et al. (1997): The role of cockroach allergy and exposure to cockroach allergen in causing morbidity among inner-city children with asthma. N Engl J Med 336: 1356-1363.

4. Sun BQ, Lai XX, Gjesing B, et al. (2010): Prevalence of sensitivity to cockroach allergens and IgE cross-reactivity between cockroach and house dust mite allergens in Chinese patients with allergic rhinitis and asthma. Chin Med J 123: 3540-3544.

5. Zheng YW, Lai XX, Zhao de Y, et al. (2015): Indoor Allergen Levels and Household Distributions in Nine Cities Across China. Biomed Environ Sci 28: 709-717.

6. Thangam Sudha V, Arora N, Sridhara S, et al. (2007): Biopotency and identification of allergenic proteins in Periplaneta americana extract for clinical applications. Biologicals 35 : 131-137.

7. He S, Zhang Z, Zhang H, et al. (2011): Analysis of properties and proinflammatory functions of cockroach allergens Per a 1.01s. Scand J Immunol 74: 288-295.

8. Wu HQ, Liu ZG, Ran PX, et al. (2007): Expression, purification, and immunological characterization of Cr PI. Protein Pept Lett 14: 881-885.

9. Mindykowski B, Jaenicke E, Tenzer S, et al. (2010): Cockroach allergens Per a 3 are oligomers. Dev Comp Immunol 34: 722-733.

10. Tan YW, Chan SL, Ong TC, et al. (2009): Structures of two major allergens, Bla g 4 and Per a 4, from cockroaches and their IgE binding epitopes. J Biol Chem 284: 3148-3157.

11. Wei JF, Yang H, Li D, et al. (2014): Preparation and identification of Per a 5 as a novel American cockroach allergen. Mediators Inflamm 2014: 591468.

12. Chen H, Yang HW, Wei JF, et al. (2014): In silico prediction of the T-cell and IgE-binding epitopes of Per a 6 and Bla g 6 allergens in cockroaches. Mol Med Rep 10: 2130-2136.

13. Yang H, Kong X, Wei J, et al. (2012): Cockroach allergen Per a 7 down-regulates expression of Toll-like receptor 9 and IL-12 release from P815 cells through PI3K and MAPK signaling pathways. Cell Physiol Biochem 29: 561-570.

14. Sookrung N, Chaicumpa W, Tungtrongchitr A, et al. (2006): Periplaneta americana arginine kinase as a major cockroach allergen among Thai patients with major cockroach allergies. Environ Health Perspect 114: 875-880.

15. Yang H, Chen H, Jin M, et al. (2016): Molecular cloning, expression, IgE binding activities and in silico epitope prediction of Per a 9 allergens of the American cockroach. International journal of molecular medicine. Int J Mol Med 38: 1795-1805.

16. Sudha VT, Arora N, Gaur SN, et al. (2008): Identification of a serine protease as a major allergen (Per a 10) of Periplaneta americana. Allergy 63: 768-776.

17. Tong X, Guo M, Jin M, et al. (2016): In silico epitope prediction, expression and functional analysis of Per a 10 allergen from the American cockroach. International journal of molecular medicine. Int J Mol Med 38: 1806-1814.

18. Fang Y, Long C, Bai X, et al. (2015): Two new types of allergens from the cockroach, Periplaneta americana. Allergy 70: $1674-1678$.

19. Chen JJ, Xia LX, Liu ZG, et al. (2008): [Cloning, expression and purification of allergen arginine kinase from Periplaneta americana and its allergic activity]. Zhongguo Ji Sheng Chong Xue Yu Ji Sheng Chong Bing Za Zhi 26: 356-360.

20. Olsson S, van Hage-Hamsten M, Whitley P, et al. (1998): Expression of two isoforms of Lep d 2, the major allergen of
Lepidoglyphus destructor, in both prokaryotic and eukaryotic systems. Clin Exp Allergy 28: 984-991.

21. Emery VC (1992): Baculovirus expression vectors : choice of expression vector. Methods Mol Biol 8: 287-307.

22. An S, Chen L, Wei JF, et al. (2012): Purification and characterization of two new allergens from the venom of Vespa magnifica. PLoS One 7: e31920.

23. An S, Ma D, Wei JF, et al. (2011): A novel allergen Tab y 1 with inhibitory activity of platelet aggregation from salivary glands of horseflies. Allergy 66: 1420-1427.

24. Sanz ML, Gamboa PM, Antepara I, et al. (2002): Flow cytometric basophil activation test by detection of CD63 expression in patients with immediate-type reactions to betalactam antibiotics. Clin Exp Allergy 32: 277-286.

25. Sainte-Laudy J, Vallon C, Guérin JC (1994): [Analysis of membrane expression of the CD63 human basophil activation marker. Applications to allergologic diagnosis]. Allerg Immunol (Paris) 26: 211-214.

26. Pruzansky JJ, Grammer LC, Patterson R, Roberts M (1983): Dissociation of IgE from receptors on human basophils. I. Enhanced passive sensitization for histamine release. J Immunol 131: 1949-1953.

27. Blank S, Michel Y, Seismann H, et al. (2011): Evaluation of different glycoforms of honeybee venom major allergen phospholipase A2 (Api m 1) produced in insect cells. Protein Pept Lett 18: 415-422.

28. Soldatova LN, Tsai C, Dobrovolskaia E, et al. (2007): Characterization of the $\mathrm{N}$-glycans of recombinant bee venom hyaluronidase (Api m 2) expressed in insect cells. Allergy Asthma Proc 28: 210-215.

29. Tomalski MD, King TP, Miller LK (1993): Expression of hornet genes encoding venom allergen antigen 5 in insects. Arch Insect Biochem Physiol 22: 303-313.

30. Borer AS, Wassmann P, Schmidt M, et al. (2012): Crystal structure of Sol I 2: a major allergen from fire ant venom. J Mol Biol 415: 635-648.

31. Langner KF, Jarvis DL, Nimtz M, et al. (2009): Identification, expression and characterisation of a major salivary allergen (Cul s 1) of the biting midge Culicoides sonorensis relevant for summer eczema in horses. Int J Parasitol 39: 243-250.

32. Shoji H, Hanawa M, Shibuya I, et al. (1996): Production of recombinant mite allergen Der fI in insect cells and characterization of products-removal of pro-sequence is essential to IgE-binding activity. Biosci Biotechnol Biochem 60: 621-625.

33. Teo AS, Ramos JD, Lee BW, et al. (2006): Expression of the Blomia tropicalis paramyosin Blo t 11 and its immunodominant peptide in insect cells. Biotechnol Appl Biochem 45: 13-21.

34. Xu W, Simons FE, Peng Z (1998): Expression and rapid purification of an Aedes aegypti salivary allergen by a baculovirus system. Int Arch Allergy Immunol 115: 245-251.

35. Peng Z, Xu W, Lam H, et al. (2006): A new recombinant mosquito salivary allergen, rAed a 2: allergenicity, clinical relevance, and cross-reactivity. Allergy 61: 485-490.

36. Chapman MD, Smith AM, Vailes LD, et al. (2000): Recombinant allergens for diagnosis and therapy of allergic disease. J Allergy Clin Immunol 106: 409-418. 